NBER WORKING PAPERS SERIES

\title{
ASSET BUBBLES AND ENDOGENOUS GROWTH
}

Noriyuki Yanagawa

Gene M. Grossman

Working Paper No. 4004

\section{NATIONAL BUREAU OF ECONOMIC RESEARCH 1050 Massachusetts Avenue \\ Cambridge, MA 02138 \\ February 1992}

We are grateful to Ben Bernanke, Elhanan Helpman, Jean Tirole, and Harald Uhlig for comments on an earlier draft. Grossman thanks the National Science Foundation for financial support. This paper is part of NBER's research program in Growth. Any opinions expressed are those of the authors and not those of the National Bureau of Economic Research. 
NBER Working Paper \#4004

February 1992

\title{
ASSET BUBBLES AND ENDOGENOUS GROWTH
}

\begin{abstract}
We study the interaction between productive and nonproductive savings in an economy that grows in the long run due to endogenous improvements in labor productivity. As in the neoclassical growth setting with overlapping generations studied by Tirole (1985), asset bubbles can exist in an economy with endogenous growth provided they are not too large and that the growth rate in the equilibrium without bubbles exceeds the interest rate. Since the growth rate in the bubbleless equilibrium is endogenous, the existence condition reflects parameters of tastes and technology. We find that bubbles, when they exist, retard the growth of the economy, perhaps even in the long run, and reduce the welfare of all generations born after the bubble appears.
\end{abstract}

Noriyuki Yanagawa

Department of Economics

Princeton University

Princeton, NJ 08544

and University of Tokyo
Gene M. Grossman Woodrow Wilson School

Princeton University

Princeton, NJ 08544 and NBER 


\section{Introduction}

Can the market price of an asset deviate from market fundamentals (i.e., the present discounted value of dividend payments) in a vorld populated by rational, far-sighted investors? Tirole (1982) has shown that it cannot, if the economy comprises a finite number of infinitely-lived traders, while Vallace (1980) and Tirole (1985) have shown that the same is true in a non-growing economy no matter how long are investors' trading horizons. But Tirole (1985) and Veil (1987) have established that "bubbles" sometimes can exist in the general equilibrium of a growing economy with overlapping generations.

$\triangle$ rational investor will only hold an asset priced differently than its fundamentals if she expects that the bubble component will yield at least a normal rate of return; i.e., that it will grow at least at the real rate of interest. But if bubbles grow at the rate of interest in every period, eventually their value will exceed the income of the young generations who must purchase these assets from the old, unless the income of these generations is growing at least as fast. Tirole (1985) investigated the conditions under which a Diamond (1965) economy with an expanding population would grow fast enough to allow for the existence of bubbles in asset prices.1 He related the existence condition to the intertemporal efficiency of the general equilibrium without bubbles.2 of course, in the Diamond economy with a neoclassical production function and no technological progress, per capita incomes stagnate in the long run.

1Yeil (1987) used a similar framerork to study "stochastically-bursting bubbles."

${ }^{2}$ See Tirole (1990) and Blanchard and Fischer (1989, ch.5) for excellent introductions to this literature. 
In this paper, we extend Tirole's (1985) results to include economies that grow in the long run at an endogenous rate. $1 \mathrm{~s}$ is well known by now, long-run growth can be sustained in an economy in which real returns to whatever capital goods are being accumulated (physical, knowledge, or human) are bounded from below by a number that exceeds the discount rate. In other words, there must be non-decreasing returns to accumulable factors in the long run. These non-decreasing returns may be inherent to the production technology (e.g., Rebelo 1991, Jones and Manuelli 1990) or they may arise due to externalities generated in the process of capital accumulation (e.g., Romer 1986, 1990; Lucas 1988). We choose a simple specification that includes externalities from physical capital (following Romer 1986) and investigate the existence conditions for bubbles and the effects that bubbles have on the growth rate of the economy and on the velfare of the various generations of agents. ${ }^{3}$ Ve find that the conditions under which bubbles can exist are similar to those identified by Tirole (1985), but that bubbles are not so benign in this setting as they are in the Diamond economy with an exogenous growth rate.

\section{A Diamond- Romer Economy Vithout Bubbles}

As in Diamond (1965), agents live for two periods. They work, consume, and save when they are young, and enjoy the fruits of their savings when they are old. Each period a new generation of young is born, endowed with a fixed amount of potential working time, which it supplies inelastically in the labor

\footnotetext{
3Ye choose this specification with capital externalities to bring out the similarities with the Tirole (1985) analysis of the Diamond economy. But the existence conditions for bubbles are similar in economies with other sources of endogenous long-run growth; see Yanagara (1991).
} 
market. They use their labor income to buy output for consumption and investment purposes and to purchase the existing capital stock from the old. Ve assume for now that capital goods are the only store of value. For simplicity, we assume that the economy's population is constant through time and equal to $2 \mathrm{~L}$.

$A$ representative member of the generation born at time $t$ consumes $c_{y t}$ units of the homogeneous final good when young, and $c_{0 t+1}$ units of this good when old. She chooses her consumption profile to maximize a utility function, $U\left(c_{y t}, c_{o t+1}\right)$, subject to an intertemporal budget constraint. Letting $r_{t+1}$ be the rate of return (or real interest rate) on savings invested at time $t$, the constraint can be written as

$$
c_{y t}+\frac{c_{0 t+1}}{1+r_{t+1}}=I_{t},
$$

where $I_{t}$ is the individual's labor income earned at time $t$.

The consumer's optimization yields equality between the marginal rate of intertemporal substitution, $\sigma_{1} / \sigma_{2}$, and one plus the interest rate, $1+r_{t+1}$, as usual. This equation generates an implicit savings function, $s_{t}=$ $s\left(I_{t}, r_{t+1}\right)$. Ve assume henceforth that individual preferences represented by $D(\cdot)$ are homothetic. Then $s\left(\lambda I_{t}, r_{t+1}\right)=\lambda s\left(I_{t}, I_{t+1}\right)$.

Firms hire the available labor force, $L$ (half the population, namely the young generation), and the available aggregate capital stock, $\mathbb{R}_{t}$, and produce the homogeneous output, $Y_{t} \cdot \Delta$ firm $i$ that rents $k_{t}^{i}$ units of capital from the old generation that owns $i t$ and that employs $L_{t}^{i}$ young workers generates net output (after accounting for capital depreciation) of 


$$
Y_{t}^{i}=F\left[K_{t}^{i}, A\left(K_{t}\right) L^{i}\right]
$$

where $A(\cdot)$ represents labor productivity, $A^{\prime}>0$. Here we have incorporated a positive spillover from the size of the aggregate capital stock to the productivity of workers in individual firms, in the manner suggested by Arrow (1962) and formalized by Sheshinski (1967) and Romer (1986). We assume that $F(\cdot, \cdot)$ exhibits constant returns to scale and that firms behave competitively. In hiring capital, the individual firm ignores its tiny influence on the aggregate capital stock and thus on the productivity of its oun workers. Thus, each firm hires capital up to the point where its (private) marginal product equals the rental rate, $r_{t}$, and it hires workers until their marginal product equals the wage rate. In view of the homogeneity of degree one of $F(\cdot, \cdot)$, this gives the following relationships at the aggregate level:

$$
\begin{aligned}
& r_{t}=F_{1}\left(K_{t}, A_{t} L\right)=f^{\prime}\left(k_{t}\right) \\
& r_{t}=F\left(K_{t}, A_{t} L\right)-R_{t} F_{1}\left(R_{t}, A_{t} L\right)=f\left(k_{t}\right)-k_{t} f^{\prime}\left(k_{t}\right),
\end{aligned}
$$

where $A_{t}=A\left(K_{t}\right), k_{t} \equiv R_{t} / A_{t} L$ (capital per unit of efficiency labor), and $f\left(k_{t}\right) \equiv F\left(k_{t} / A_{t} L, 1\right)$. Combining (2) and (3) gives a relationship between equilibrium factor prices,

4As we noted in the introduction, we are not wedded to this specification of the technology. Alternative formulations that preserve long-run incentives for capital accumulation would serve equally vell. For a general discussion of what is needed to sustain long-run growth in a model of capital accumulation, see Grossman and Helpman (1991, ch.2). 
(4)

$$
w_{t}=\phi\left(r_{t}\right) .
$$

Product market equilibrium obtains when aggregate investment equals aggregate savings, i.e., the sum of desired savings by the young and desired dissavings by the old. Since the old wish to dissave their entire holdings of capital, $\mathbb{K}_{t}$, this implies $\mathbb{R}_{t+1}-x_{t}=s\left(w_{t} \Lambda_{t} L, r_{t+1}\right)-R_{t}$, or

$$
\mathbb{R}_{t+1}=s\left(w_{t} \Lambda_{t} L, r_{t+1}\right) \text {. }
$$

Equations (3), (4), and (5) determine the dynamic evolution of the economy (factor prices and capital stock) from any initial stock of capital, $\mathbb{K}_{0}$.

In order to ensure the existence of a steady state for this economy, we take a particular functional form for the capital externality, making it linear in the aggregate capital stock; i.e.,

$$
\Lambda\left(\mathbb{R}_{t}\right)=\mathbb{R}_{t} / \mathbf{a} .
$$

Vithout further loss of generality, we normalize the size of the population to two, so that $L=1$. Then $k_{t}=a$ for all $t$, and (3) and (4) imply

$$
r_{t}=\rho \quad \text { for all } t,
$$

where $\rho \equiv f^{\prime}(a)$. Now since $s(\cdot, \cdot)$ is homogeneous of degree one in its first 
argument, $s\left(w_{t} A_{t} L, r_{t+1}\right)=\Lambda_{t} L s\left(w_{t}, r_{t+1}\right)$. Then, after substituting (6), $\left(3^{\prime}\right)$, and $\left(4^{\prime}\right)$, equation (5) becomes

$$
K_{t+1}=K_{t} s[\phi(\rho), \rho] / a \text {. }
$$

The capital stock grows at the rate

$$
g_{t}=s / a-1
$$

where $s \equiv s[\phi(\rho), \rho]$. By $(6)$, labor productivity $\Delta(\cdot)$ grows at this same rate and since $F(\cdot, \cdot)$ has constant returns to scale, so does per capita income.

Before leaving this section, we note that the dynamic equilibrium without bubbles is not Pareto efficient. For suppose that at time $t$ the old vere to consume as in the above equilibrium while the young saved an additional amount ds. This would increase the capital stock at $t+1$ by $d s$ and would generate additional output of $\left(d Y_{t+1} / d K_{t+1}\right) d s=\left(F_{1}+F_{2} / a\right) d s>r_{t+1} d s$. If the entirety of this extra output in period $t+1$ were given to the (then) old, then the utility of this. generation would rise (since it has set its marginal rate of intertemporal substitution equal to $1+r_{t+1}$, the extra output in the second period of life yields more utility than the loss from the consumption foregone in the first period) while no generation would lose. Of course, the inefficiency of the market equilibrium reflects the fact that (small) individual agents have no incentive to incorporate the spillover effect from capital in their private investment decisions. 


\section{Existence of Asset Bubbles}

Ve now assume that the generation that is old at time 0 possesses $\mathbf{Y}$ paper assets that are intrinsically vorthless. That is, the assets produce no real output and therefore generate no dividends. The old attempt to sell these assets to the young at a positive price $p_{0}$ (in terms of goods) for each piece of paper. Vould a rational, foresighted, young investor be willing to purchase one of these assets? Only if she believed that she could resell the asset when old (i.e., in period 1) to a member of the next young generation for a price that includes a real rate of return comparable to that available on other assets. The real (gross) rate of return on alternative assets is $1+r_{1}$ units of output in period 1 . Therefore, the young investor in period 0 is willing to buy the intrinsically useless asset if she expects its price in period 1 to be at least $p_{1}=\left(1+r_{1}\right) p_{0}$. Similarly, the young generation in any period $t$ must expect the price of the paper to be $p_{t}\left(1+r_{t+1}\right)$ in period $t+1$, if it is to acquire the asset from the old generation at that time at a price $p_{t}$. If all of these expectations for capital gains on the asset can be fulfilled, then the intrinsically useless paper can be traded indefinitely; that is, there can exist a bubble.

Let $B_{t}=p_{t}$ be the aggregate value of the bubble at time $t$, and assume for the moment that the self-fulfilling prophecy can be realized. By the condition of no-arbitrage between bubbles and other assets, we have

$$
B_{t+1}=\left(1+I_{t+1}\right) B_{t} \text {. }
$$

Ve define $b_{t} \equiv B_{t} / A_{t} L$ as the aggregate value of the bubble per efficiency unit of labor. 
The young generation must purchase the entirety of existing bubbles from the old generation in each period. The condition for goods market equilibrium becomes

$$
R_{t+1}-R_{t}=A_{t} \operatorname{ls}\left(B_{t}, r_{t+1}\right)-\left(B_{t}+R_{t}\right)
$$

the left-hand side is net investment, while the right-hand side is the difference between savings by the young and dissavings by the old (the term in parentheses on the far right of [9]). Note that (3') and (4') continue to describe factor prices when $\Lambda_{t}=\mathbb{K}_{t} / a$ and $L=1$. Substituting these expressions into (9), ve derive $\mathbb{k}_{t+1}=t_{t}\left(\bar{s}-b_{t}\right)$, or $\mathbb{R}_{t+1} / \mathbb{R}_{t}=\left(s-b_{t}\right) / a$. Thus,

$$
g_{t}=\frac{\bar{s}-b_{t}}{a}-1
$$

Ve now discuss whether, given an initial bubble of size $B_{0}$ such that $b_{0}=B_{0} / A\left(K_{0}\right)$, the dynamics described $b_{y}(8)$ and $(10)$ are sustainable. If they are, then an initial bubble of size $B_{0}$ can exist in an economy that has an initial capital stock of $\mathbb{R}_{0}$. Note that labor productivity grows at rate $g_{t}$, so (8) and (3') imply

$$
b_{t+1}=\frac{1+\rho}{1+g_{t}} b_{t} .
$$

Substituting (10) into (11) gives a single, recursive equation for the 
evolution of the value of the bubble per efficiency unit of labor,

$$
b_{t+1}=a(1+\rho) \frac{b_{t}}{s-b_{t}} .
$$

The curve labelled $B B$ in the top part of figure 1 depicts this relationship between the (normalized) size of the bubble in successive periods. Clearly, when this curve lies above the 45 degree line, the bubble is groving relative to the stock of efficiency labor (and, therefore, aggregate output), whereas when the curve lies below the 45 degree line, the bubble is shrinking relative to efficiency labor.

Ve see from the figure that, if the initial size of the bubble is such that $b_{0}<b^{*}$, the normalized bubble shrinks monotonically over time. In this case, the assumed existence of the initial bubble does not lead to any contradiction. Isymptotically, the bubble becomes arbitrarily small in relation to the stock of efficiency labor, and the economy converges to the steady state described in section 2 . If, alternatively, the initial size of the bubble is such that $b_{0}>b^{*}$, then the normalized bubble grows monotonically over time. Eventually, at some $T, b_{T}>\Sigma$. But then the aggregate savings of the young do not suffice to allow them to acquire the bubble from the old generation at the required price. The old at $T$ would have foreseen this eventuality at T-1, and so would not have purchased the bubble from the (then) old generation at that time. The bubble unravels back to time 0 ; i.e., an initial bubble of the assumed size cannot be sustained. Finally, it is possible that $b_{0}=b^{*}$. Then the bubble and the economy remain in fixed proportion to one another and the economy immediately enters a steady 
state.

Evidently, bubbles can exist in this economy provided their initial size is no larger than $b^{*}$. Notice the similarity between the existence condition for bubbles here and that described by Tirole (1985) for the Dianond economy. No bubble of any size will be possible if the BB curve is steeper at the origin than the 45 degree line. The slope of the $B B$ curve at the origin equals $a(1+\rho) / s$. Thus bubbles can exist if an only if $s / a-1>\rho$. But $\bar{s} / \mathrm{a}-1$ is the economy's grouth rate in the absence of any bubbles, while $\rho$ is the real interest rate, so here, as in Tirole, the existence of bubbles requires that the gronth rate exceeds the interest rate in the equilibrium of the bubbleless economy.

of course, in the model with exogenous growth, the bubble cannot affect the long-run growth rate. Here, that is not true. The bottom portion of the figure illustrates the effect that bubbles have on the growth rate. The line GG, depicting equation (10), shows the relationship between the (normalized) size of the bubble at time $t$ and the growth rate. If the initial bubble happens to be of size $B^{*}$ such that $B^{*} / A\left(\mathbb{R}_{0}\right) L=b^{*}$, then the bubble permanently lowers the rate of growth from $g_{t}=s / a-1$ to $g_{t}=\rho$. (Smaller initial bubbles reduce the rate of growth in every period, but the depression of the growth rate asymptotically approaches zero as $t$ grows large.) The reason is straightforward. The existence of the asset bubble diverts savings avay from productive investment in capital, and it is capital investment that drives long-run growth in the Diamond-Romer model. 


\section{Bubbles and Intertemporal Efficiency}

Tirole $(1985,1990)$ has shown for the Diamond economy that the asymptotically bubbly equilibrium (in which the bubble remains in fixed proportion to the size of the economy in the long run) is intertemporally efficient. The bubble eliminates overaccumulation of capital, which can arise in the Diamond model because living generations cannot trade with the as yet unborn. In fact, the bubbles can exist in that setting if and only if the bubbleless equilibrium is inefficient.

One might expect a different result in our model of externality-based endogenous growth. Is we have seen at the end of section 2 , the economy without bubbles has less capital formation than is required for intertemporal efficiency. Bubbles divert savings from productive use in financing capital accumulation into an unproductive store of value and thereby exacerbate the existing distortion in the market equilibrium.

Suppose that a bubble of size $B_{0}$ first appears in the economy at time 0 . What are the velfare implications? The generation that is old at time 0 benefits of course, as their sale of the new asset to the young enables them to consume more than othervise. The labor income of the generation that is young at time 0 depends upon $\mathbb{R}_{0}$ and $\Lambda_{0}$, both of which are predetermined at time 0 . Their savings accrue interest at rate $r_{t+1}=\rho$ with or without the bubble. So this generation, which has (indirect) utility given by $V\left[\phi(\rho) \Lambda_{0}, \rho\right]$, is not affected by the bubble. $\Delta 11$ subsequent generations are harmed, however, as growth of labor productivity is reduced by the bubble and therefore each generation born after time 0 earns less labor income than it would have othervise.

It is interesting to note that the generation that is born at time 1 , by 
itself, suffers income losses from the bubble that are sufficiently large that this generation could more than compensate the initial old for their gain from the bubble, if only there were a way to effect this intergenerational transfer. The bubble allows the initial old to increase their consumption in period 0 by $B_{0}$. The slowdown in productivity growth causes the generation that is young at time 1 to lose vage income in period 1 of $\left(\hat{\Lambda}_{1}-\Lambda_{1}\right) \phi(\rho)=$ $A_{0}\left(\hat{\mathrm{B}}_{0}-\mathrm{g}_{0}\right) \phi(\rho)$, where a circumflex indicates a variable in the equilibrium without bubbles. Noting the growth rates recorded in (7) and (10), we find $\hat{\mathrm{g}}_{0^{-}} \mathrm{g}_{0}=\mathrm{b}_{0} / \mathrm{a}$. Thus, the income loss at time 1 equals $\mathrm{B}_{0} \phi(\rho) / \mathrm{a}$. Since this comes one period later than the gain to the initial old, the value of this income loss discounted back to time 0 is $B_{0} \phi(\rho) / a(1+\rho)$, where we have used the market interest rate (which equals also the intertemporal rate of substitution for every generation) to perform the discounting. Now we calculate the difference between the discounted loss to the young at time 1 and the gain to the initial old as

$$
\frac{\mathrm{B}_{0} \phi(\rho)}{\mathrm{a}(1+\rho)}-\mathrm{B}_{0}=\frac{\mathrm{B}_{0}}{\mathrm{a}(1+\rho)}[\phi(\rho)-\mathrm{a}(1+\rho)] .
$$

The existence condition for a sustainable bubble requires $s / a-1>\rho$, or $s>a(1+\rho)$. Since the wealth constraint requires $w=\phi(\rho)>s$, the term in square brackets on the far right-hand side of (13) is positive. This establishes our claim. ${ }^{3}$

SIn fact, it can be shown that any generation born after the period in which the bubble forms suffers a greater loss than the gain to the initial old generation (even after allowing for discounting). The loss to the generation born at time $n$, discounted to time zero, is 
But the fact that the young born at time 1 could bribe the old at time 0 to "retire" the bubble asset does not mean that the bubble can be made to disappear. The problem is that these two generations do not trade with one another. The transfer from the young at time 1 to the old at time 0 must be effected through the generation that is young at time 0 . When this generation pays the bribe to the initial old, it will want to collect $(1+\rho)$ times the amount that it has laid out from the young at time 1 . In the interim, it has an "IOO" that is exactly like the bubble asset. 6 The young at time 0 divert savings from capital formation in order to pay the bribe, with the result that the potential gain from the intergenerational transfer scheme disappears. The harm caused by the bubble to generations born after time 0 cannot be avoided by a simple tax/subsidy scheme that redistributes income across generations.7

$$
\frac{a_{0} \phi(\rho)}{a^{n}(1+\rho)^{n}}\left[s^{n}-\prod_{i=0}^{i=n}\left(s-b_{i}\right)\right]
$$

Since $\phi(\rho)>\Xi>a(1+\rho)$, the difference between the loss to the generation born at time $n$ and the gain to the old at time 0 exceeds

$$
\frac{\Delta_{0}}{s^{n}}\left(\bar{s}-b_{0}\right)\left[\bar{s}^{n}-\prod_{i=1}^{i=n}\left(\bar{s}-b_{i}\right)\right]>0 .
$$

OThis IOO is like a national debt. O'Connell and Zeldes (1986) and Tirole (1990) have discussed the analogy between asset bubbles and public debt in overlapping generations models. The analogy remains apt in the present context. See Alogoskoufis and van der Ploeg (1990) for an analys is of the effects of public debt in an externalities-based model of endogenous growth.

TVelfare of all generations can be improved, hovever, by a policy that stimulates investment and causes individuals to internalize the externality associated with capital formation. 


\section{IY. Conclusions}

In settings where long-run growth is driven by investments in physical, human, or knowledge capital, the existence of an unproductive asset - - one that yields a financial return but does not contribute to the production of real output - can be harmful to grouth. The unproductive asset, or bubble, attracts savings away from more productive uses. Each new generation purchases the asset at least partly at the expense of investment in growthpromoting capital.

In this paper, we have examined the conditions under which asset bubbles can exist in a simple model of endogenous growth. As in the neoclassical growth setting, a bubble can survive only if the equilibrium growth rate exceeds the interest rate in the bubbleless economy. Here, hovever, the equilibrium grouth rate, like the interest rate, is determined by parameters of tastes and technology. Bubbles are more likely to be possible when households are patient (i.e., savings propensities are high for a given interest rate) and when investments in capital generate spillover benefits to labor productivity. When bubbles do exist, they retard economic growth along the transition path to the steady state and possibly even in the long run. The bubbles also harm all generations born after the period in which the asset first appears, and to an extent that exceeds the gain to the generation that benefits from the bubble.

In our model, a bubble can exist only on intrinsically useless assets. That is, there cannot be any bubble in the price of capital. This is because new units of an asset must have the same price as old, and it is always 
possible to create a new unit of capital at a cost of one unit of output.8 Thus, competition from potential new supply prevents exponential growth in the price of real capital.

This raises the fundamental question about asset bubbles: what determines their supply? Every individual is willing to exchange a worthless piece of paper for a positive amount of goods. If asset bubbles do appear in the economy, is there any way to predict ahead of time how many and which ones? Is there any way to prevent their formation in situations where their existence will retard growth? These questions remain to be answered.

${ }^{8}$ This argument assumes that different units of capital, which are economically indistinguishable in our model, also are physically indistinguishable. Otherwise, there could be bubbles in the prices of specific units of capital. One might say, in such a case, that the capital is priced at its fundamental value, but that the "names" of specific pieces of equipment (which are intrinsically useless assets) acquire value as bubbles. 


\section{References}

Alogoskoufis, George S. and Frederick van der Ploeg (1990) "Endogenous Growh and Overlapping Generations," Discussion Paper No. 90/26, Birkbeck College, University of London.

Arrow, Kenneth J. (1962) "The Economic Implications of Learning by Doing," Revier of Economic Studies 29: 155-173.

Blanchard, Olivier J. and Stanley Fischer (1989) Lectures in Macroeconomics. Cambridge, MA: MIT Press.

Diamond, Peter A. (1965) "National Debt in a Neoclassical Growth Yodel," American Economic Revier 55: 1126-1150.

Grossman, Gene M. and Elhanan Belpman (1991) Innovation and Growth in the Global Economy. Cambridge, MA: MT Press.

Jones, Larry E. and Rodolfo Manuelli (1990) "A Convex Model of Equilibrium Growth," Journal of Political Economy 98: 1008- 1038.

Lucas, Robert E., Jr. (1988) "On the Mechanics of Economic Development," Journal of Monetary Economics 22: 2-42.

0'Conne11, Stephen and Stephen Zeldes (1988), "Rational Ponzi Games," International Economic Review 29: 431-450.

Romer, Paul צ. (1986) "Increasing Returns and Long-Run Growth," Journal of Political Economy 94: 1002-1037.

Romer, Paul M. (1990) "Endogenous Technological Progress," Journal of Political Economy 98: S71-S102.

Rebelo, Sergio (1991) "Long Run Policy Analysis and Long Run Growth," Journal of Political Economy 99: 500-521.

Sheshinski, Eitan (1967) "Optimal Accumulation with Learning by Doing," in $\mathbf{K}$. Shell, ed., Essays on the Theory of Optimal Economic Growth. Cambridge, MA: MIT Press.

Tirole, Jean (1982) "On the Possibility of Speculation under Rational Expectations," Econometrica 50: 1163-1181.

Tirole, Jean (1985) "Asset Bubbles and Overlapping Generations," Econometrica 53: $1499-1528$.

Tirole, Jean (1990) "Intertemporal Efficiency, Intergenerational Transfers, and Asset Pricing: In Introduction," in P. Champsaur et al., eds., Essays in Honor of Edmond Malinvaud, Volume 1: Yicroeconomics. Cambridge, MA: IIT Press. 
Vallace, Neil (1980) "The Overlapping Generations Yodel of Fiat Koney," in J. Rareken and N. Vallace, eds., Yodels of Yonetary Economics.

Yinneapolis: Federal Reserve Bank of Minneapolis.

Veil, Phillippe (1987) "Confidence and the Real Value of Yoney in

Overlapping Generations Yodels," Quarterly Journal of Economics 102: 1- 22 .

Yanagawa, Noriyuki (1991) "Bubbles and Economic Grouth," mimeo. 
</ref_section> 


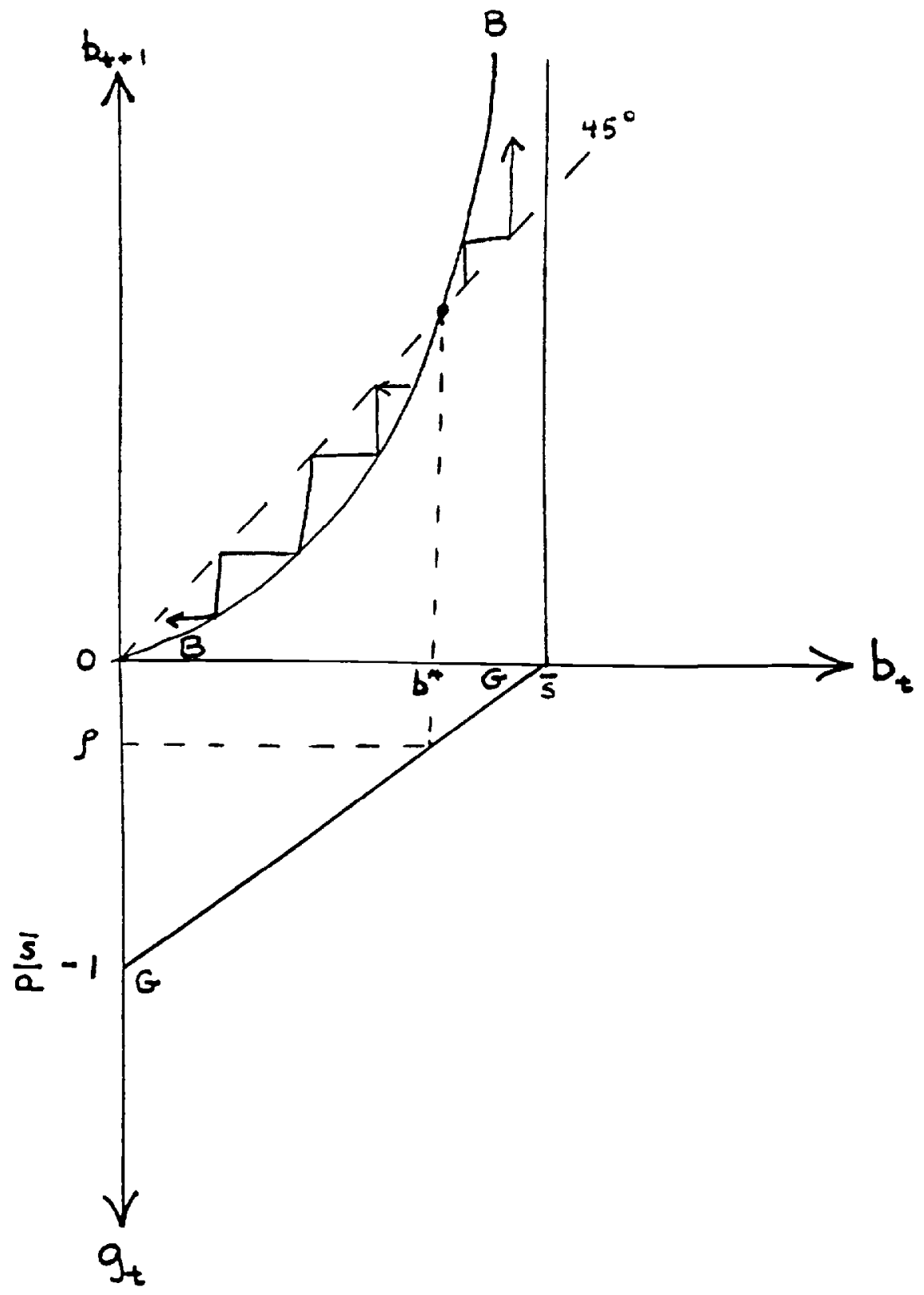

Figure 1 